\title{
Marital status and abortion among young women in Rupandehi, Nepal
}

\author{
Kathryn L Andersen ${ }^{1 *}$, Ram Chandra Khanal ${ }^{2}$, Alexandra Teixeira' ${ }^{1}$ Shailes Neupane ${ }^{3}$, Sharad Sharma ${ }^{2}$,
} Valerie N Acre ${ }^{1}$ and Maria F Gallo ${ }^{4}$

\begin{abstract}
Background: Despite liberalization of the Nepal abortion law, young women continue to experience barriers to safe abortion services. We hypothesize that marital status may differentially impact such barriers, given the societal context of Nepal.

Methods: We evaluated differences in reproductive knowledge and attitudes by marital status with a probabilitybased, cross-sectional survey of young women in Rupandehi district, Nepal. Participants $(N=600)$ were surveyed in 2012 on demographics, romantic experiences, media habits, reproductive information, and abortion knowledge and attitudes. We used logistic regression to assess differences by marital status, controlling for age.

Results: Participants, who comprised never-married (54\%) and ever-married women (45\%), reported good access to basic reproductive health and abortion information. Social desirability bias might have prevented reporting of premarital romantic and sexual activity given that participants reported more premarital activities for their friends than for themselves. Only 45\% knew that abortion was legal, and fewer ever-married women were aware of abortion legality. Never-married women expected more negative responses from having an abortion than ever-married women.

Conclusions: Findings highlight the need for providing sexual and reproductive health care information and services to young women regardless of marital status.
\end{abstract}

Keywords: Adolescents, Induced abortion, Nepal, Pregnancy

\section{Background}

Since legalizing abortion in 2002 [1], Nepal has made striking progress in rolling out induced abortion services, establishing comprehensive abortion care at public-sector facilities, and providing safe abortion care services to $>500,000$ Nepali women [2]. The relatively liberal law, which allows for legal termination of pregnancy up to 12 weeks of gestation-or up to 18 weeks in cases of result of rape or incest or at any time if medically indicated-appears to have contributed to an overall national decline in maternal mortality [3]. However, unsafe abortion remains a health concern. Abortion accounted for an estimated 14\% of maternal deaths at health care facilities in 2008-2009 [4], which underscores that even in settings where abortion is legal, women may resort to unsafe procedures. In general,

\footnotetext{
* Correspondence: andersenk@ipas.org

${ }^{1}$ Ipas, 300 Market St., Suite 200, Chapel Hill, NC 27516, USA

Full list of author information is available at the end of the article
}

barriers to accessing safe abortion care can include negative provider attitudes, fear of repercussion, lack of access to comprehensive sexuality education, limited financial resources, cost of care, transportation, thirdparty involvement laws, and concerns over privacy and confidentiality [5].

Adolescents, in particular, often face challenges in accessing abortion. Young women who obtain abortion care tend to access it later in pregnancy than older women [6] and are more likely to delay seeking help for abortion-related complications [7]. These delays likely are attributable, at least in part, to stigma surrounding adolescent sexuality [8-10]. Many youth lack the negotiation and decision-making skills necessary for abstaining from unsafe sexual practices [11]. In Nepal, only $4.2 \%$ of adolescents report using a modern form of contraception [12], and youth describe embarrassment from discussing sexual health with parents, relatives and senior community members [13]. Adolescents also perceive 
sexual health service providers as judgmental and raise concerns about lack of confidentiality.

Less research has been conducted on the relationship between marital status and abortion. The patriarchal and patrilineal nature of society in Nepal translates into a strong preference for sons $[14,15]$, which could influence women's decision-making about and access to abortion. Having a male offspring is considered crucial for continuing the family lineage, providing financial support to parents as they age, and carrying out other roles (e.g., lighting funeral pyres) while female children are often viewed as a financial burden (e.g., because of dowry costs). Married women in Nepal perceive great pressure from their husband and parents-in-law to bear a son [16], and abortion for sex selection has emerged as a concern $[17,18]$. Despite the illegality of abortion for this purpose in Nepal [1], we hypothesize that the intense pressure that married women are under to have a male child could contribute to a greater acceptance of abortion-regardless of the reason in individual cases-for married women compared to unmarried women.

Despite cultural norms against premarital sexual activity in Nepal [19], the practice appears to be common $[20,21]$. Social proscriptions against sex outside of marriage, though, could limit unmarried women's access to contraception or safe abortion services. For example, government hospitals and some pharmacies distribute condoms only to married individuals [22], and their purchase by unmarried women is considered culturally unacceptable. A study conducted at the largest women's hospital in Nepal found that most induced abortions were performed on married women [23]. This disparity by marital status could reflect a greater need for abortion services among married women or could result from unmarried women being less likely to access safe services. We hypothesized that regardless of their age, unmarried women in a patriarchal society such as Nepal might face different barriers to obtaining safe abortion care than their married counterparts.

\section{Methods}

We conducted a cross-sectional survey during April and May 2012 using a probability-based household sample of 600 women aged 16-24 years in Rupandehi district, Nepal. The district was selected for its strong community partners (for planning future interventions), its geographic accessibility, and its diverse representation of the nation's castes and ethnicities and major religions, namely, Hinduism, Muslim and Buddhism. One of 75 districts in Nepal, Rupandehi district is located in the Lumbini Zone in the Western Development Region and is rapidly urbanizing, with a population growth rate of 3.05 percent in [24].
Trained female interviewers administered a survey to collect information on participant demographics, romantic and sexual experiences, media habits, sources and types of reproductive information, and abortion knowledge and attitudes. The survey was developed in English and translated into Nepali before being pretested with approximately 20 young women from a nearby geographic area, who were expected to be similar to the target population. All interviews were conducted in a private setting. Only women who provided written consent were eligible for participation. The National Health Research Council (NHRC) in Nepal and Allendale institutional review board in the U.S. approved the protocol.

\section{Sampling}

The sample was selected with a two-stage cluster sampling design. In the first stage, the clusters (wards) were identified using the probability proportional to size (PPS) method among all wards within the intervention area (using ward populations from 2001 census data) [25]. The sample was conducted from 37 of Rupandehi's 71 main socio-political units (including 69 village development committees (VDCs) and two municipalities, which are each subdivided by population size into approximately nine wards. After listing all intervention wards in alphabetic order by VDC, municipality and ward name, we used the PPS method to select 30 wards.

In the second stage of sampling, we randomly selected 600 respondents from households within each sampled ward. First, we consulted with key informants from the selected wards to create lists of household heads within each selected ward. Then, we used simple random sampling (using a random start and sampling interval) to select 20 households from each list. Using simple sketched maps of the selected wards to locate households, interviewers administered a screening questionnaire to the head or knowledgeable person of the sampled household to determine the residence of any women 16-24 years of age. If multiple women meeting the age criterion resided in the household, only one was randomly selected for participation using a lottery technique. If the selected respondent was unavailable after three visits or if she declined to consent, the nearest neighboring household was substituted.

\section{Analysis}

We report simple descriptive statistics for the factors assessed. For socio-demographic characteristics and reproductive history, we assessed differences between never- married and ever-married women using chisquared tests and $\mathrm{t}$ tests. We used logistic regression models adjusted for age (in years) in order to identify potential differences by marital status in media habits, 
type and sources of information on abortion and contraception, and abortion knowledge and perceptions.

\section{Results}

\section{Study sample}

We visited a total of 805 households, of which 611 households had at least one woman 16-24 years of age. In 11 of the households, no woman was available to be interviewed due to not being present at the time of the interview $(n=6)$, being sick or physically weak $(n=3)$ or declining participation $(\mathrm{n}=2)$. Thus, the analysis is based on interviews with 600 participants.

About $54 \%$ of the participants were never married while the remainder were currently married $(45 \%)$ or were separated, divorced or widowed (1\%). Mean age at marriage was 16.4 years (standard deviation [SD], 2.6; range, 8-23). Never- and ever-married women differed in their demographic characteristics and reproductive history (Table 1). The mean age of respondents was 19.2 years (SD, 2.7) with a younger mean age among those who had never been married compared with that of ever-married women (17.8 and 20.9 years, respectively; p-value $<0.01)$. More never-married women $(67 \%)$ had completed $\geq 6$ grades of education than their evermarried counterparts $(33 \% ; \mathrm{p}=0.01)$. Few of the nevermarried women reported sexual debut and contraception use, and none reported having been pregnant or having had an abortion.

\section{Romantic experiences}

Few participants reported having had romantic experiences (i.e., relationships, time alone with a boy, kissing,

Table 1 Socio-demographic characteristics and reproductive history, overall and by marital status, Rupandehi district, 2012

\begin{tabular}{|c|c|c|c|c|c|c|c|}
\hline \multirow{3}{*}{ Age, median (range) } & \multirow{2}{*}{\multicolumn{2}{|c|}{$\begin{array}{l}\text { Total } \\
(N=600)\end{array}$}} & \multirow{2}{*}{\multicolumn{2}{|c|}{$\begin{array}{l}\text { Never married } \\
(\mathrm{N}=325)\end{array}$}} & \multirow{2}{*}{\multicolumn{2}{|c|}{$\begin{array}{l}\text { Ever married } \\
(\mathrm{N}=275)\end{array}$}} & \multirow{3}{*}{$\begin{array}{l}p^{*} \\
<0.0\end{array}$} \\
\hline & & & & & & & \\
\hline & 19 & $(16-24)$ & 17 & $(16-24)$ & 21 & $(16-24)$ & \\
\hline & No. & (\%) & No. & (\%) & No. & (\%) & \\
\hline \multicolumn{8}{|l|}{ Education completed } \\
\hline$<$ Grade 6 & 203 & $(33.8)$ & 58 & $(28.6)$ & 145 & $(71.4)$ & $<0.01$ \\
\hline$\geq$ Grade 6 & 397 & $(66.2)$ & 267 & $(67.3)$ & 130 & $(32.8)$ & \\
\hline \multicolumn{8}{|l|}{ Caste or ethnicity } \\
\hline Brahmin/Chhetri & 106 & $(17.7)$ & 68 & $(64.2)$ & 38 & (35.9) & \\
\hline Terai/Madhesi/Other & 241 & $(40.2)$ & 111 & $(46.1)$ & 130 & $(53.9)$ & \\
\hline Dalit & 55 & $(9.2)$ & 24 & (43.6) & 31 & $(56.4)$ & \\
\hline Newar & 5 & $(0.8)$ & 3 & $(60.0)$ & 2 & $(40.0)$ & \\
\hline Janajati & 153 & $(25.5)$ & 100 & $(65.4)$ & 53 & (34.6) & \\
\hline Muslim & 40 & $(6.7)$ & 19 & $(47.5)$ & 21 & $(52.5)$ & \\
\hline \multicolumn{8}{|c|}{ Worked in past year (cash or in-kind) } \\
\hline Yes & 76 & $(12.7)$ & 50 & $(15.4)$ & 26 & $(9.5)$ & 0.03 \\
\hline No & 524 & $(87.3)$ & 275 & $(84.6)$ & 249 & $(90.6)$ & \\
\hline \multicolumn{8}{|l|}{ Ever had sex } \\
\hline Yes & 282 & $(47.0)$ & 7 & $(2.2)$ & 275 & $(100.0)$ & $<0.01$ \\
\hline No & 318 & $(53.0)$ & 318 & $(97.9)$ & 0 & $(0.0)$ & \\
\hline \multicolumn{8}{|l|}{ Ever used contraception } \\
\hline Yes & 137 & $(22.8)$ & 5 & $(1.5)$ & 132 & $(48.0)$ & $<0.01$ \\
\hline No & 463 & $(77.2)$ & 320 & $(98.5)$ & 143 & $(52.0)$ & \\
\hline \multicolumn{8}{|l|}{ Gravidity } \\
\hline 0 & 400 & $(66.7)$ & 325 & $(100.0)$ & 75 & $(27.3)$ & $<0.01$ \\
\hline$\geq 1$ & 200 & $(33.3)$ & 0 & $(0.0)$ & 325 & $(72.7)$ & \\
\hline \multicolumn{8}{|l|}{ Abortion history } \\
\hline 0 & 581 & $(96.8)$ & 325 & $(100.0)$ & 256 & $(93.1)$ & 0.01 \\
\hline$\geq 1$ & 19 & (3.2) & 0 & $(0.0)$ & 19 & $(6.9)$ & \\
\hline
\end{tabular}

*P-value from unadjusted chi-squared test or $t$ test for difference by marital status. 
or sex) outside of the context of marriage or attempting to end an unwanted pregnancy (Figure 1). However, when asked about the experiences of their friends, participants gave more accounts of each activity, with $49 \%$ of participants reporting having a friend with a romantic relationship outside of marriage, $20 \%$ having a friend have sex outside of marriage and $8 \%$ having a friend attempt abortion.

\section{Media habits}

More than half of respondents (53\%) reported viewing television daily, with another $24 \%$ watching television at least once per week. Furthermore, 38\% and 23\% of women listened to the radio either daily or at least once per week, respectively. Print media were relatively popular among participants, with $40 \%$ reporting newspaper or magazine use. Fewer women (10\%) reported any internet use. Among those using the internet, most did so in their own homes (68\%) and many accessed the social website Facebook (86\%). Reported attendance at youth or school clubs was low (5\%). Notably, a higher proportion of never-married participants engaged with media sources than ever-married participants, particularly with regard to daily television ( $60 \%$ vs. $45 \%$, respectively; $\mathrm{p}<0.01$ ), daily radio ( $43 \%$ vs. $32 \%$, respectively; $\mathrm{p}<0.01$ ) and print media ( $52 \%$ vs. $25 \%$, respectively; $\mathrm{p}<0.01$ ).

\section{Types and sources of reproductive information}

Most participants reported receiving information about contraceptive methods (89\%) and sources of services $(85 \%)$ in the past year (Table 2). Fewer were informed on their costs $(28 \%)$, directions on use $(11 \%)$ and side effects (11\%). Regarding abortion, while most women reported receiving information in the past year on where to obtain a safe abortion (76\%), fewer were informed about abortion methods (52\%), costs (31\%), and possible complications (43\%). Most participants were able to identify medical abortion (82\%) and dilation and curettage $(69 \%)$ as methods of abortion while few (8\%) had heard of manual vacuum aspiration (MVA). Marital status did not appear to be related to the type of contraceptive information received in the past year. In contrast, married women were more likely to report receiving information on abortion costs $(\mathrm{p}=<0.01)$, possible complications $(p=0.02)$, legality $(p=0.02)$ and awareness of abortion methods $(\mathrm{p}=0.02)$ than never-married women after controlling for age.

Women received reproductive-health information from a variety of sources (Figure $2 \mathrm{a}$ and $\mathrm{b}$ ). Not surprisingly, the most popular source of information on contraception and abortion was an interpersonal one: a friend or neighbor ( $67 \%$ and $56 \%$, respectively). Television and radio also were common sources of information on contraception (52\% and $50 \%$, respectively) and, to a lesser extent, on abortion (45\% and $27 \%$, respectively). Female community health volunteers (FCHVs) were the most frequently cited among the professional and community sources for information on contraception (33\%) and abortion (24\%). Sources of information differed by marital status. For example, never-married participants were more likely to rely on television or radio for both contraception and abortion information whereas married women were more likely to receive information from FCHVs and health care providers.

\section{Abortion knowledge and attitudes}

Participants had low levels of knowledge about the legal status of abortion in Nepal: only $45 \%(\mathrm{~N}=271)$ of respondents knew that termination of pregnancy was legal. Furthermore, the details of the law were not well known. For example, only $28 \%$ of women knew that 16 was the

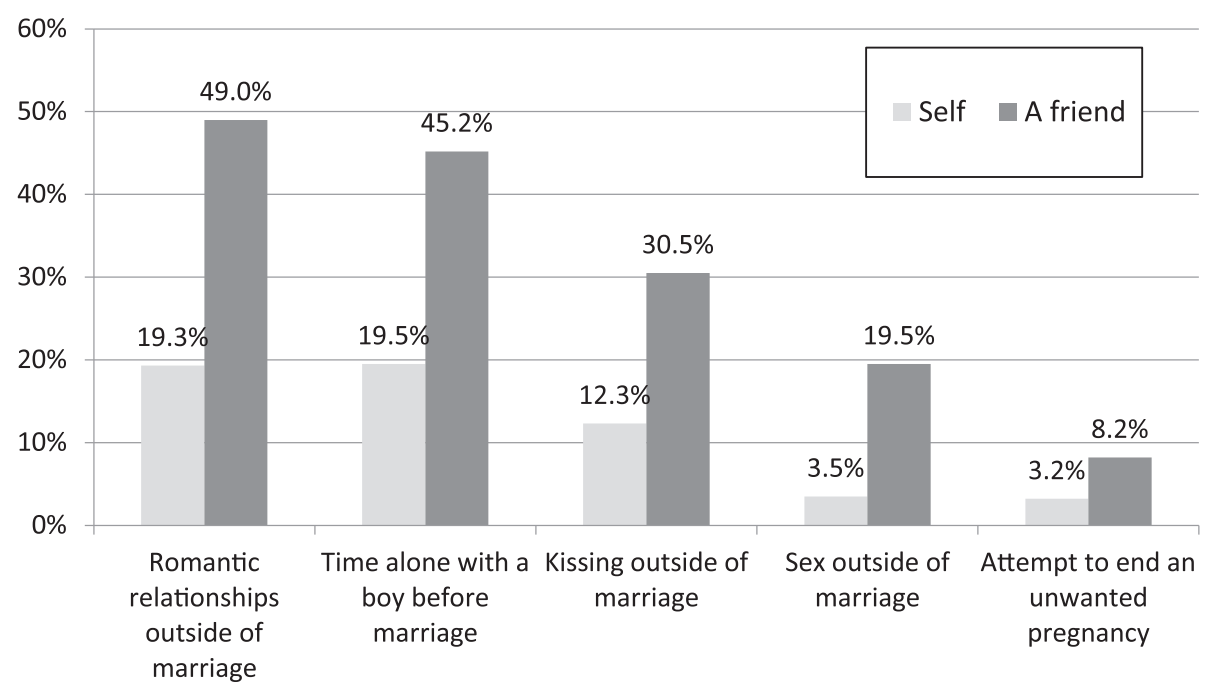

Figure 1 Romantic and sexual experiences involving self or a friend, Rupandehi district, 2012. 
Table 2 Information received and awareness of methods, overall and by marital status, Rupandehi district, 2012

\begin{tabular}{|c|c|c|c|c|c|c|c|}
\hline & \multicolumn{2}{|c|}{$\frac{\text { Total }}{(\mathrm{N}=600)}$} & \multirow{2}{*}{\multicolumn{2}{|c|}{$\frac{\text { Never married }}{(\mathrm{N}=325)}$}} & \multirow{2}{*}{\multicolumn{2}{|c|}{$\frac{\text { Ever married }}{(\mathrm{N}=275)}$}} & \multirow[b]{3}{*}{$p^{*}$} \\
\hline & $(\mathrm{N}=$ & & & & & & \\
\hline & No. & $(\%)$ & No. & $(\%)$ & No. & (\%) & \\
\hline \multicolumn{8}{|l|}{ Contraception information received in past year } \\
\hline Methods & 535 & $(89.2)$ & 290 & $(89.2)$ & 245 & $(89.1)$ & 0.44 \\
\hline Sources & 512 & $(85.3)$ & 278 & $(85.5)$ & 234 & $(85.1)$ & 0.45 \\
\hline Costs & 131 & $(27.5)$ & 66 & $(20.3)$ & 65 & (23.6) & 0.50 \\
\hline Directions on use & 165 & $(11.0)$ & 92 & $(28.3)$ & 73 & (26.6) & 0.38 \\
\hline Possible side effects & 66 & $(11.0)$ & 40 & $(12.3)$ & 26 & $(9.5)$ & 0.20 \\
\hline \multicolumn{8}{|l|}{ Abortion information received in past year } \\
\hline Methods & 311 & $(51.8)$ & 165 & $(50.8)$ & 146 & $(53.1)$ & 0.61 \\
\hline Sources for safe abortion & 458 & $(76.3)$ & 249 & $(76.6)$ & 209 & $(76.0)$ & 0.23 \\
\hline Costs & 184 & $(30.7)$ & 75 & $(23.1)$ & 109 & (39.6) & $<0.01$ \\
\hline Possible complications & 255 & $(42.5)$ & 143 & $(44.0)$ & 112 & $(40.7)$ & 0.02 \\
\hline Stories of other women's induced abortions & 136 & $(22.7)$ & 80 & $(24.6)$ & 56 & (20.4) & 0.13 \\
\hline Abortion-related mortality & 102 & $(17.0)$ & 60 & $(18.5)$ & 42 & (15.3) & 0.08 \\
\hline Legality of abortion & 75 & $(12.5)$ & 49 & $(15.1)$ & 26 & $(9.5)$ & 0.02 \\
\hline \multicolumn{8}{|l|}{ Aware of abortion methods } \\
\hline No methods & 74 & $(12.3)$ & 35 & $(10.8)$ & 39 & $(14.2)$ & \\
\hline Yes, any method & 526 & $(87.7)$ & 290 & $(89.2)$ & 236 & (85.8) & 0.02 \\
\hline Medication abortion & 494 & $(82.3)$ & 270 & $(83.1)$ & 224 & (81.5) & \\
\hline Manual vacuum aspiration & 42 & $(7.0)$ & 25 & $(7.7)$ & 17 & $(6.2)$ & \\
\hline Dilation \& curettage & 412 & $(68.7)$ & 227 & $(69.9)$ & 185 & $(67.3)$ & \\
\hline
\end{tabular}

*P-value for difference by marital status from logistic regression analysis adjusted for age.

legal age of consent for abortion (i.e., younger women are required to be accompanied by a legal guardian). Only 33\% of participants knew that being unmarried did not automatically make abortion illegal and only $37 \%$ knew that having an unintended pregnancies as the result of contraceptive failure does not preclude women from accessing legal abortions. Ever-married women consistently were less informed than never-married women even after controlling for age (Figure 3).

Respondents were asked whether they agreed or disagreed with a series of statements related to abortion practices (Table 3). Opinions were favorable for a number of important items such as support if friends needed an abortion (86\%); feeling comfortable in talking with health care providers about abortion (74\%); and feeling comfortable initiating talks with my friends about abortion-related issues (70\%). However, participants believed that abortion costs and acceptability differ by the marital status of the woman involved. Most respondents believed that doctors usually charge more for an abortion for unmarried women $(68 \%)$ and that abortion is more acceptable for married women (47\%) than for unmarried women (16\%) in their communities.
Furthermore, never-married women appeared more comfortable with the idea of abortion than ever-married women. More never-married women than their evermarried counterparts reported commonly talking about abortion-related issues with their friends (70\% vs. 65\%, respectively; $\mathrm{p}=0.01$ ); being comfortable initiating talks with their friends about abortion-related issues (73\% vs. $67 \%$, respectively; $\mathrm{p}<0.01$ ); confident about their ability to help a friend find abortion services if needed (81\% vs. $74 \%$; $<<0.01)$; saying the words "vagina" and "penis" without embarrassment ( $18 \%$ vs. $11 \%$; $<<0.01)$ and supporting a friend if she needed an abortion ( $88 \%$ vs. $83 \%$; $\mathrm{p}=0.02)$. On the other hand, more never-married women than ever-married women expected to be treated badly if they had an abortion ( $70 \%$ vs. $55 \%$; p <0.01) and fewer imagined that health care workers would treat them kindly if they needed an abortion (37\% vs. $54 \%$, respectively; $\mathrm{p}<0.01$ ).

\section{Discussion}

In this household-based survey conducted in Rupandehi district in Nepal, young (16-24 years of age) women reported having good access to information on reproductive health: most women had received information on 


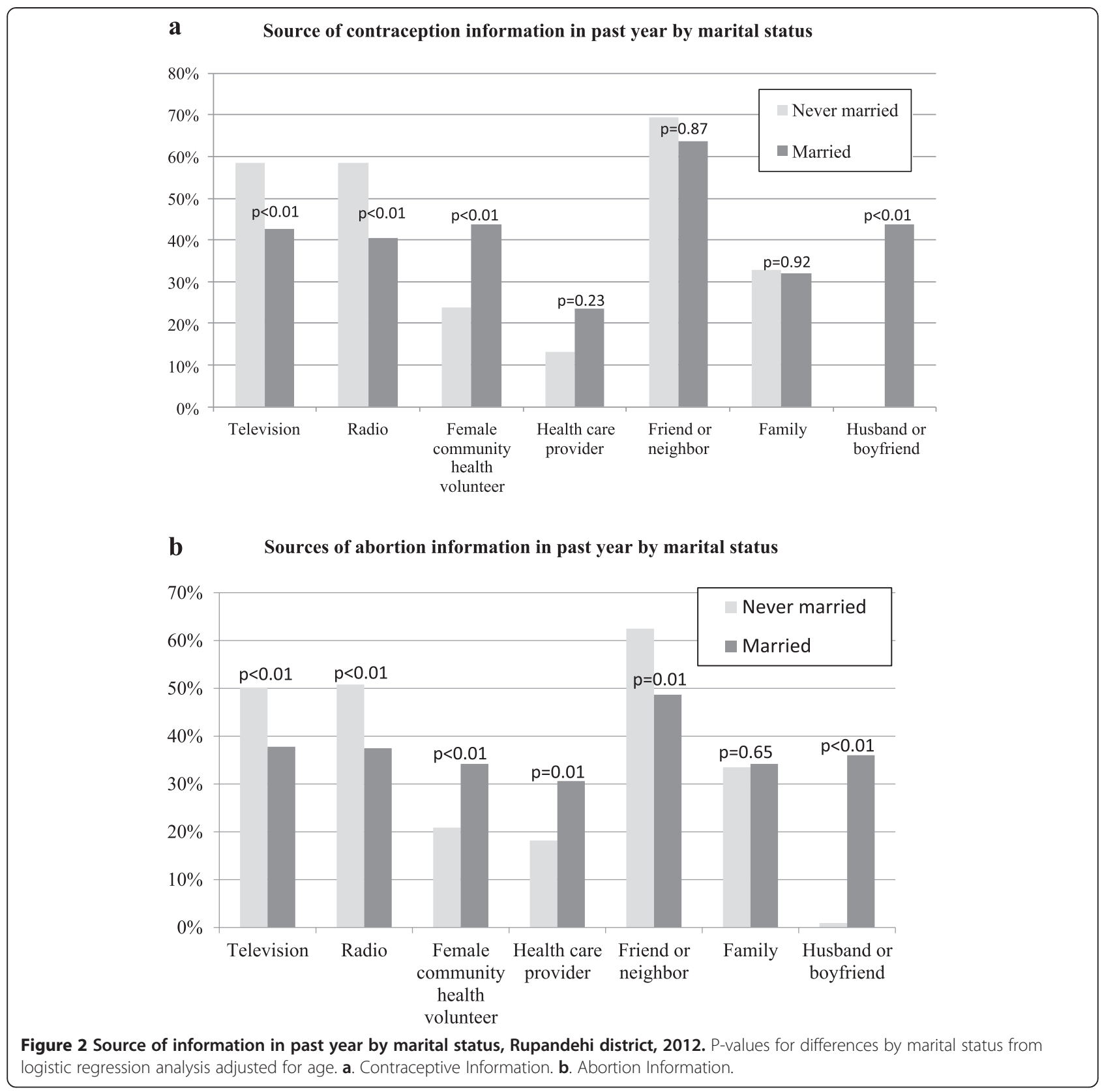

sources and methods of contraception and abortion care in the past year. Furthermore, most women (88\%) could name a method of abortion, most often medical abortion and, to a lesser extent, dilation and curettage. Few participants (7\%) mentioned MVA as a possible method. Programmatic efforts should focus on increasing young women's knowledge of MVA and equipping providers with the proper training and capacity to perform this safer alternative to dilation and curettage [26]. In Nepal, medication abortion is available at primary health centers while MVA services are accessible at higher levels of the health system. Improving women's understanding of medication abortion regimens, and the optimal gestational age for accessing these services, could further improve reproductive health outcomes.

Participants denied having engaged in romantic activity, including sexual activity, outside of marriage. However, they were much more likely to report that their friends engaged in romantic relationships, spending time alone with a boy, kissing, and sexual contact outside of marriage. These findings suggest that social desirability bias might prevent women from admitting to having premarital experiences. This interpretation is consistent with a survey of students conducted at three colleges in Nepal, in which premarital sex was reported by $45 \%$ of men but only by $4 \%$ of women [27]. Similarly, a study of 


\section{Ever married $\quad$ Never married}

Not being able to afford another child*

Not wanting another child*

Having a strong chance of serious birth defects*

Having health risks from the pregnancy*

Having pregnancy resulting from rape*

Having an accidental pregnancy (from contraceptive failure $)^{*}$

Being unmarried*

Being $<16$ years of age and accompanied by an adult*

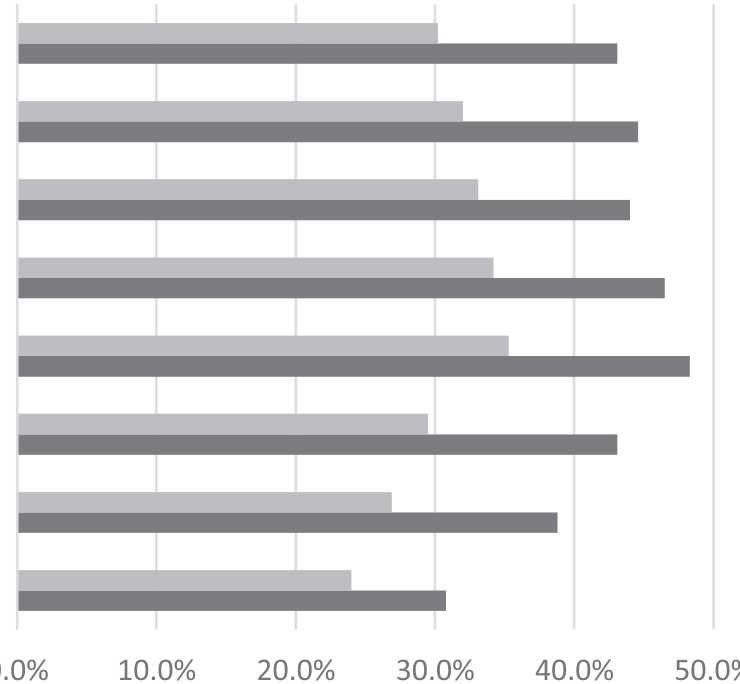

$60.0 \%$

*Indicates statistically significant differences $(\mathrm{p}<0.01)$ between ever married and never married women.

Figure 3 Knowledge of factors that affect abortion legality in Nepal by marital status, Rupandehi district, 2012.

young factory workers in Kathmandu Valley found that $35 \%$ and $16 \%$ of unmarried males and females, respectively, reported being sexually experienced [20]. Finally, in a survey of male college students, 39\% reported having had premarital sex [21]. Together with the literature, the present findings suggest that despite prevailing social norms, romantic and sexual activity among unmarried youth in Nepal, particularly in urban areas, is a reality.

Knowledge of Nepal's abortion law was low: only $45 \%$ of women were even aware that abortion is legal in

Table 3 Abortion-related perceptions, overall and by marital status, Rupandehi district, 2012

\begin{tabular}{|c|c|c|c|c|c|c|c|}
\hline \multirow[b]{3}{*}{ Agrees with statement } & \multirow{2}{*}{\multicolumn{2}{|c|}{$\begin{array}{l}\text { Total } \\
(\mathrm{N}=600)\end{array}$}} & \multirow{2}{*}{\multicolumn{2}{|c|}{$\begin{array}{l}\begin{array}{l}\text { Never } \\
\text { married }\end{array} \\
(\mathrm{N}=325)\end{array}$}} & \multirow{2}{*}{\multicolumn{2}{|c|}{$\begin{array}{l}\text { Ever } \\
\text { married } \\
(\mathrm{N}=275)\end{array}$}} & \multirow[t]{3}{*}{$P^{*}$} \\
\hline & & & & & & & \\
\hline & No. & (\%) & No. & (\%) & No. & (\%) & \\
\hline $\begin{array}{l}\text { If I needed an abortion and a facility were available in my village development committee, I would go } \\
\text { there }\end{array}$ & 411 & $(68.5)$ & 208 & $(64.0)$ & 203 & $(73.8)$ & 0.09 \\
\hline I have information about abortion methods and providers near me & 382 & $(63.7)$ & 203 & $(62.5)$ & 179 & $(65.1)$ & 0.52 \\
\hline Doctors usually charge unmarried women more for an abortion & 406 & $(67.7)$ & 219 & $(67.4)$ & 187 & $(68.0)$ & 0.87 \\
\hline Abortions among unmarried women generally are considered acceptable in this community & 93 & $(15.5)$ & 38 & $(11.7)$ & 55 & $(20.0)$ & 0.08 \\
\hline Abortions among married women generally are considered acceptable in this community & 282 & $(47.0)$ & 152 & $(47.8)$ & 130 & $(47.3)$ & 0.36 \\
\hline Talking about abortion-related issues is common among my friends & 404 & $(67.3)$ & 226 & $(69.5)$ & 178 & $(64.7)$ & 0.01 \\
\hline If I were to have an abortion, my friends and relatives would treat me badly & 380 & $(63.3)$ & 228 & $(70.2)$ & 152 & $(55.3)$ & $<0.01$ \\
\hline If I were to go for an abortion, I imagine that the health care workers would treat me kindly & 269 & $(44.8)$ & 121 & $(37.2)$ & 148 & $(53.8)$ & $<0.01$ \\
\hline I feel comfortable talking to a medical doctor or nurse about abortion-related issues & 445 & $(74.2)$ & 241 & $(74.2)$ & 204 & $(74.2)$ & 0.14 \\
\hline I feel comfortable initiating talks with my friends about abortion-related issues & 422 & $(70.3)$ & 237 & $(72.9)$ & 185 & $(67.3)$ & $<0.01$ \\
\hline If a friend of mine wanted an abortion, I feel confident that I could help her find this service & 464 & $(77.3)$ & 262 & (80.6) & 202 & (73.5) & $<0.01$ \\
\hline I can say the words "vagina" and "penis" without feeling embarrassed & 90 & $(15.0)$ & 59 & $(18.2)$ & 31 & $(11.3)$ & $<0.01$ \\
\hline I am able to say "no" if I do not feel like having sex & 459 & $(76.5)$ & 259 & $(76.7)$ & 200 & $(72.7)$ & 0.09 \\
\hline If a friend told me that she needed an abortion, I would support her & 515 & (85.8) & 287 & $(88.3)$ & 228 & (82.9) & 0.02 \\
\hline
\end{tabular}

*P-value for difference by marital status from logistic regression analysis adjusted for age. 
Nepal, and substantial proportions of women erroneously believed that a range of conditions (e.g., marital status, having a pregnancy result from a contraceptive failure or not wanting or not being able to afford a child) would affect the legal right to an abortion. This finding is consistent with previous research documenting low levels of awareness of the legal status of abortion [28-30], including an earlier assessment in the same district, which included reports of "medical halls" where women go for unsafe abortion [31]. The lack of awareness of legal status appears to result in women seeking unsafe abortion [32]. We found that ever-married women, regardless of their age, were consistently less informed than never-married women about the legality of abortion.

Women's sources for reproductive health information also differed by marital status. Never-married women were more likely than ever-married women to report receiving contraception or abortion information in the past year from television, radio, or a friend or neighbor. In contrast, ever-married women were more likely than never-married to have obtained contraceptive or abortion information from a FCHV, health care provider or their husband. The important role that health care providers hold in disseminating information on contraception and abortion to all women should be emphasized and strengthened.

Although most (74\%) of the young women in this survey reported feeling comfortable in talking to a health care provider about abortion-related issues, about $23 \%$ (with no difference found by marital status) did not think that they could decline sex if they wanted to. Furthermore, women reported being embarrassed by references to male and female genitals. This lack of selfefficacy regarding sex and fertility is a potential barrier to seeking proper reproductive health care.

Women's perceptions of abortion-related factors also differed by their marital status. In general, never-married women tended to be more comfortable and supportive of abortion. They were more likely to talk about abortion topics with their friends and were more comfortable with these discussions than were married-women. They also were more likely to indicate that they would support a friend who needed an abortion or feel confident that they could help a friend obtain the procedure. However, never-married women expected to experience more negative responses from health care workers, family and friends if they were to have an abortion than were married-women. Furthermore, both never and evermarried women agreed that abortion among unmarried women was not accepted in their community $(88 \%$ and $80 \%$, respectively). Abortion among unmarried women in Nepal is strongly condemned, and providers have voiced concerns that the legalization of abortion is leading to an increase in utilization of services among unmarried women [33]. Both society, in general, and health care providers are more accepting of abortion among married women. For example, a qualitative study of abortion providers in Kathmandu Valley revealed that even though providers perceived abortion for sex selection to be unethical, they still empathized with married women who faced pressure to have a male offspring and thought that abortion for this purpose should be available for some women [34].

\section{Conclusions}

Given the early mean age of childbearing among women in Nepal [35], sexual activity among adolescents clearly is common and underscores the importance of access to contraceptive and abortion care among youth. Less attention, though, has been directed to differences in the provision of information and services to unmarried women. This could be especially important in patriarchal societies, which could be expected to have strong norms against sexual agency of unmarried women. The present study demonstrated substantial differences in abortion information, experiences and perception by marital status and highlights the need for the provision of sexual and reproductive health care knowledge and services to all women regardless of marital status.

\section{Abbreviations}

FCHV: Female community health volunteer; MVA: Manual vacuum aspiration; NHRC: Nepal Health Research Council; PPS: Probability proportional to size;

SD: Standard deviation; US: United States; VDC: Village development committee.

\section{Competing interests}

The authors declare that they have no competing interests.

\section{Authors' contributions}

Authors contributed in the following ways: study design (KA, RK, AT, SN, SS), implementation (RK, SN, SS), analysis (KA, VA, MG) and writing (KA, MG). All authors reviewed and approved the final version of the manuscript.

\section{Acknowledgements}

Department of Health Services, Family Health Division commissioned this assessment with technical and financial support of Ipas and field execution of Valley Research Group.

\section{Author details}

${ }^{1}$ Ipas, 300 Market St., Suite 200, Chapel Hill, NC 27516, USA. ${ }^{2}$ Ipas Nepal, PO Box 11621, Tewa Tower, 3rd Floor, Teku, Kathmandu, Nepal. ${ }^{3}$ Valley Research Group, PO Box 4112, Kathmandu, Nepal. ${ }^{4}$ Division of Epidemiology, The Ohio State University, College of Public Health, 324 Cunz Hall 1841 Neil Avenue, Columbus, $\mathrm{OH}$ 43210, USA.

Received: 24 July 2014 Accepted: 30 January 2015

Published online: 22 February 2015

References

1. Thapa S. Abortion law in Nepal: the road to reform. Reprod Health Matters. 2004;12(24 Suppl):85-94.

2. Samandari G, Wolf M, Basnett I, Hyman A, Andersen K. Implementation of legal abortion in Nepal: a model for rapid scale-up of high-quality care. Reprod Health. 2012;9(7):1742-4755.

3. Henderson JT, Puri M, Blum M, Harper CC, Rana A, Gurung G, et al. Effects of abortion legalization in Nepal, 2001-2010. PLoS One. 2013;8(5):e64775. 
4. Pradhan A, Suvedi BK, Sharma SK, Puri M, Poudel P, Chitrakar SR, et al. Nepal maternal mortality and morbidity study 2008/2009. Kathmandu, Nepal: Family Health Division, Department of Health Services, Ministry of Health and Population, Government of Nepal; 2012.

5. Turner KL, Börjesson E, Huber A, Mulligan C. Abortion care for young women: a training toolkit. Ipas: Chapel Hill, NC; 2011.

6. Finer LB, Frohwirth LF, Dauphinee LA, Singh S, Moore AM. Timing of steps and reasons for delays in obtaining abortions in the United States. Contraception. 2006;74(4):334-44.

7. World Health Organization, Trust CMA, UNICEF. Orientation programme on adolescent health for health-care providers. Geneva, Switzerland: World Health Organization; 2006.

8. Klingberg-Allvin M, Nga NT, Ransjo-Arvidson AB, Johansson A. Perspectives of midwives and doctors on adolescent sexuality and abortion care in Vietnam. Scand J Public Health. 2006;34(4):414-21.

9. Klingberg-Allvin M, Van Tam V, Nga NT, Ransjo-Arvidson AB, Johansson A. Ethics of justice and ethics of care values and attitudes among midwifery students on adolescent sexuality and abortion in Vietnam and their implications for midwifery education: a survey by questionnaire and interview. Int J Nurs Stud. 2007:44(1):37-46.

10. Mngadi PT, Faxelid E, Zwane IT, Hojer B, Ransjo-Arvidson AB. Health providers' perceptions of adolescent sexual and reproductive health care in Swaziland. Int Nurs Rev. 2008;55(2):148-55.

11. World Health Organization, Department of Reproductive Health and Research. Sexual relations among young people in developing countries: evidence from WHO case studies. Geneva, Switzerland: World Health Organization; 2001

12. Ministry of Health and Population (MOHP), New ERA, ICF International Inc. Nepal demographic and health survey 2011. Kathmandu, Nepal: Ministry of Health and Population, New ERA and ICF International, Calverton, Maryland; 2012.

13. Regmi PR, van Teijlingen E, Simkhada P, Acharya DR. Barriers to sexual health services for young people in Nepal. J Health Popul Nutr. 2010;28(6):619-27.

14. Leone T, Matthews Z, Dalla Zuanna G. Impact and determinants of sex preference in Nepal. Int Fam Plan Perspect. 2003;29(2):69-75.

15. Uprety S, Jha N, Poudel IS, Pokharel PK, Poudel M, Niraula SR. Impact and determinants of gender preference in Duhavi VDC of eastern Nepal. JNMA J Nepal Med Assoc. 2011;51(181):28-33.

16. Chhetri UD, Ansari I, Bhandary S, Adhikari N. Sex preferences among mothers delivering at Patan Hospital. Kathmandu Univ Med J. 2011;9(4):229-32.

17. Frost MD, Puri M, Hinde PRA. Falling sex ratios and emerging evidence of sex-selective abortion in Nepal: evidence from nationally representative survey data. BMJ Open. 2013;3:e002612.

18. Center for Research on Environment Health and Population Activities (CREHPA). Sex selection: pervasiveness and preparedness in Nepal. Kathmandu, Nepal: CREHPA; 2007.

19. Mathur S, Malhotra A, Mehta M. Adolescent girls' life aspirations and reproductive health in Nepal. Reprod Health Matters. 2001;9(17):91-100.

20. Puri M, Cleland J. Sexual behavior and perceived risk of HIV/AIDS among young migrant factory workers in Nepal. J Adolesc Health. 2006;38(3):237-46.

21. Adhikari R, Soonthorndhada K, Prasartkul P. Correlates of unintended pregnancy among currently pregnant married women in Nepal. BMC Int Health Hum Rights. 2009;9:17

22. Ghimire L, Smith WC, van Teijlingen ER. Utilisation of sexual health services by female sex workers in Nepal. BMC Health Serv Res. 2011;11(79):1472-6963.

23. Thapa S, Neupane S, Basnett I, Ramnarayan K, Read E. Women having abortion in urban Nepal: 2005 and 2010 compared. Kathmandu Univ Med J. 2012;10(39):8-13.

24. Central Bureau of Statistics (CBS), International Centre for Integrated Mountain Development (ICIMOD/MENRIS). Districts of Nepal: indicators of development. Kathmandu, Nepal: International Centre for Integrated Mountain Development; 2003.

25. Central Bureau of Statistics. National population and housing census 2011, Vol 2. National planning commission secretariat. Kathmandu: Central Bureau of Statistics; 2012.

26. World Health Organization. Safe abortion: technical policy guidance for health systems. 2nd ed. Geneva, Switzerland: World Health Organization; 2012.

27. Gyan Bahadur BC, Basel PL. Premarital sex behaviors among college youths of Kathmandu Nepal. KUMJ. 2013;41(1):27-31.

28. Bart Johnston H. Abortion practice in India: a review of literature. Mumbai, India: Centre for Enquiry into Health and Allied Themes; 2002.
29. Ganatra B, Banerjee SK. Expanding community-based access to medical abortion in Jharkhand: a pre-intervention baseline survey in selected two blocks of Ranchi and Khunti districts. New Delhi, India: Ipas India; 2010.

30. Thapa S, Sharma SK, Khatiwada N. Women's knowledge of abortion law and availability of services in Nepal. J Biosoc Sci. 2014;46(2):266-77.

31. Karki K, Subedi A, Chaudhary R, Chapagain D, Bajracharya S. Young women and abortion in Rupandehi: a situation assessment report. Lalitpur, Nepal: SOLID Nepal; 2011.

32. Rocca CH, Puri M, Dulal B, Bajracharya L, Harper CC, Blum M, et al. Unsafe abortion after legalisation in Nepal: a cross-sectional study of women presenting to hospitals. BJOG. 2013;120(9):1075-83.

33. Puri M, Lamichhane P, Harken T, Blum M, Harper CC, Darney PD, et al. "Sometimes they used to whisper in our ears": Health care workers' perceptions of the effects of abortion legalization in Nepal. BMC Public Health. 2012;12:297.

34. Möller A, Öfverstedt S, Siwe K. Proud, not yet satisfied: the experiences of abortion service providers in the Kathmandu Valley Nepal. Sex Reprod Health. 2012;3(4):135-40.

35. Khatiwada N, Silwal PR, Bhadra R, Tamang T. Sexual and reproductive health of adolescents and youth in Nepal: trends and determinants: further analysis of the 2011 Nepal demographic and health survey. Calverton, Maryland: Nepal Ministry of Health and Population, New ERA and ICF International; 2013.

\section{Submit your next manuscript to BioMed Central and take full advantage of:}

- Convenient online submission

- Thorough peer review

- No space constraints or color figure charges

- Immediate publication on acceptance

- Inclusion in PubMed, CAS, Scopus and Google Scholar

- Research which is freely available for redistribution 